\title{
The effect of errorless learning on quality of life in patients with Korsakoff's syndrome
}

\author{
This article was published in the following Dove Press journal: \\ Neuropsychiatric Disease and Treatment \\ Number of times this article has been viewed
}

\author{
Yvonne CM Rensen' \\ Jos IM Egger ${ }^{2,3}$ \\ Josette Westhoff ${ }^{\prime}$ \\ Serge JW Walvoort' \\ Roy PC Kessels 1,3,4 \\ 'Center of Excellence for Korsakoff \\ and Alcohol-Related Cognitive \\ Disorders, Vincent van Gogh \\ Institute for Psychiatry, Venray, the \\ Netherlands; ${ }^{2}$ Center of Excellence \\ for Neuropsychiatry, Vincent van \\ Gogh Institute for Psychiatry, Venray, \\ the Netherlands; ${ }^{3}$ Donders Institute \\ for Brain, Cognition, and Behavior, \\ Radboud University, Nijmegen, \\ the Netherlands; ${ }^{4}$ Department \\ of Medical Psychology, Radboud \\ University Medical Center, Nijmegen, \\ the Netherlands
}

Background: Errorless learning (EL) is a promising rehabilitation principle for (re)learning instrumental activities in patients with amnesia, including patients with Korsakoff's syndrome (KS). Successfully (re)learning tasks might improve the sense of competence and independence, and subsequently the quality of life. Quality of life in patients with KS has received limited attention, and no studies have been conducted to experimentally examine the effect of EL on quality of life in patients in this patient group.

Materials and methods: The QUALIDEM, an observation scale for quality of life, was completed by professional nurses before and after EL training in a group of fifty-one patients with KS. This scale was also completed for a group of thirty-one control patients receiving care as usual but no EL training.

Results: Quality of life was significantly increased on eight of the nine subscales in the Korsakoff group who participated in an EL training. There was a trend toward a significant increase in "positive affect" (ie, the ninth subscale). In contrast, no changes over time were found on any of the subscales in the control group that did not participate in any EL training.

Conclusion: Despite severe memory impairments, patients with KS still have the potential to (partially) (re)learn tasks using EL. This potential should be exploited, as the successes of (re)-learning might improve the quality of life of Korsakoff patients in nursing homes.

Keywords: Korsakoff's syndrome, errorless learning, quality of life, memory

\section{Introduction}

Errorless learning (EL) is a method for teaching patients with severe memory impairments everyday tasks. The occurrence of errors during learning is prevented by breaking down the targeted task into small steps, modeling the task steps, providing verbal cues, discouraging participants from guessing, correcting errors immediately, fading cues carefully, and rehearsing retrieved information. ${ }^{1,2}$ The efficacy of EL has been established in patients with dementia and acquired brain injury. ${ }^{1,2}$ The findings from the few studies that have used EL principles in patients with Korsakoff's syndrome (KS) are mostly positive..$^{3-5}$

$\mathrm{KS}$ is an irreversible, neuropsychiatric disorder resulting from thiamine deficiency and depletion following years of chronic alcohol abuse. It is characterized by disproportionate learning and memory impairments, relative to other features of cognitive functioning. ${ }^{6-8}$ Generally, executive dysfunctions are also present. ${ }^{9}$ The severe memory impairments and executive dysfunctions in patients with $\mathrm{KS}$ have serious effects on daily life functioning. Tasks once learned might be forgotten, and the ability to learn new tasks is compromised. Successfully (re)learning tasks might improve the sense of competence and independence, and subsequently the quality of life. This was, for example, demonstrated by Cohen et al. ${ }^{10}$ They explored the effects of EL in a woman with profound
Correspondence: Yvonne CM Rensen Center of Excellence for Korsakoff and Alcohol Related Cognitive Disorders, Vincent van Gogh Institute, PO Box 5 5800 AA, Venray, the Netherlands Email yrensen@vvgi.nl (c)
hereby accept the Terms. Non-commercial uses of the work are permitted without any further permission from Dove Medical Press Limited, provided the work is properly attributed. For permission hereby accept the Terms. Non-commercial uses of the work are permitted without any further permission from Dove Medice
for commercial use of this work, please see paragraphs 4.2 and 5 of our Terms (https://www.dovepress.com/terms.php). 
memory and executive function impairments associated with three distinct etiologies (ie, developmental disability, surgical removal of a large portion of limbic tissue, and traumatic brain injury). Cohen et $\mathrm{al}^{10}$ described that the increasing functional competence and independence significantly improved the quality of life in this patient. In contrast, another study ${ }^{11}$ did not find significant changes on self-reported quality of life (on the RAND 36-item Short Form Health Survey [RAND-36]) after adding an EL component to goal management training, compared with conventional goal management training in brain-injured patients with executive deficits. They concluded that the improvement of specific daily activities did not affect the patients' well-being. ${ }^{11}$ The RAND-36 was completed by the participant directly after training. For future studies, the authors recommended longer follow-up assessments and the inclusion of an untrained control group.

Quality of life in patients with KS has received limited attention. So far, only Oudman and $\mathrm{Zwart}^{12}$ have pioneered this field of study. Oudman and Zwart ${ }^{12}$ compared the scores on a quality-of-life observation scale (QUALIDEM) ${ }^{13,14}$ in patients with dementia or KS. The scores of the QUALIDEM subscales were linearly transformed from 0 to 100 , with higher scores indicating a higher quality of life. Oudman and Zwart $^{12}$ reported that the general quality of life was higher in patients with KS compared with patients with dementia. However, the mean quality-of-life score in the Korsakoff group could be considered moderate $(\mathrm{M}=66.8, \mathrm{SD}=13.4)$. The lowest scores were found on the subscales "care relationship" $(\mathrm{M}=55.2, \mathrm{SD}=21.9)$ and "having something to do" $(\mathrm{M}=55.1, \mathrm{SD}=33.8)$. Subsequently, Oudman and Wijnia ${ }^{15}$ performed a 20-month follow-up study on quality of life in the same sample of patients with KS. They concluded that quality of life remains relatively stable over time in this patient group. Statistically significant, yet relatively small, improvements were only found on the subscales "positive affect," "care relationship," and "feeling at home." It is unclear whether variables such as cognitive functioning are associated with quality of life in this patient group.

So far, no studies have been conducted to experimentally examine the effect of EL on different aspects of quality of life in patients with KS. Specifically, (re)learning activities with the help of a professional carer can be hypothesized to improve "care relationship" and "having something to do," that is, the aspects of quality of life that received the lowest scores in patients with KS in the Oudman and Zwart study. ${ }^{12}$ The aim of the current study was to examine the quality of life in a group of Korsakoff patients who were trained with EL technique, and in a patient-control group who received care as usual. Following the suggestion by Bertens et al, ${ }^{11}$ we included an untrained control group and included a longer follow-up assessment period. Moreover, it is important to unravel the underlying factor(s) that contribute to quality of life in patients with KS. Therefore, we examined the relation between quality of life and cognitive functioning over time.

\section{Methods \\ Participants}

Eighty-three patients with KS participated in this study. Fiftytwo patients completed the EL training and thirty-one served as controls, receiving care as usual, but no EL training. In short, patients who received EL training were trained in two instrumental tasks of daily living (eg, making coffee and brushing teeth, using an agenda). The training was completed when no improvement was observed after 3 consecutive training sessions. Professional caregivers rated the performance of the tasks before and after training on a 5-point rating scale ( $1=$ unable to execute the task, $5=$ executes task with ease). The results showed a significant improvement in the execution of tasks after the EL intervention. Improvements were found for different types of tasks (ie, activities of daily living, chores, mobility, housekeeping). The patient-control group who received care as usual did not engage in any EL training, but otherwise received the same care, as the institutions were highly comparable.

To be included in the present study, patients had to meet the criteria for Diagnostic and Statistical Manual of Diseases-5 alcohol-induced major neurocognitive disorder. ${ }^{16}$ In addition, the criteria for alcoholic KS had to be met, including having a disproportionate memory and a history of malnutrition or thiamine deficit. ${ }^{7}$ Patients older than 70 with declining Montreal Cognitive Assessment ${ }^{17}$ (MoCA) scores over time were excluded from this study because of possible dementia. Another exclusion criterion was the presence of acute psychiatric conditions, such as psychosis or major depression. Patients in the EL group were recruited from the nursing homes MeanderGroep (Kerkrade, the Netherlands) and ZorgAccent (Hellendoorn, the Netherlands). The control group was recruited from the nursing home Atlant (Beekbergen, the Netherlands). The institutions cooperate in a Dutch network for innovative Korsakoff care. Prior to the study, all patients and their legal representatives gave their written informed consent. This study was approved by the ethical committee of Atlant nursing home and the institutional review boards of all participating institutions (Atlant, MeanderGroep, and ZorgAccent).

The quality of life follow-up observations (T2) were obtained approximately 14 months after baseline observations 
(T1) and 5 months after completion of the training in the EL group, with the aim to have long follow-up assessment periods. For the control group, the follow-up observations were obtained eleven months after baseline observation.

\section{Outcome measures}

The QUALIDEM was administered as a measure of quality of life. ${ }^{13,14}$ It is an observation scale developed for patients with dementia in nursing homes and contains 37 questions that can be divided into nine subscales, and three additional questions are for further research. The subscales need to be assessed individually and are not suitable for calculating a total score. The subscales are: Caregiver relationship, positive affect, negative affect, restless behavior, positive self-image, social relations, social isolation, feeling at home, and having something to do. Caregivers rated answers on a 4-point Likert scale. For each category, a higher score means a better quality of life. Two professional carers (including the first responsible caregiver of the patient) completed the QUALIDEM together so as to control for the mixed interrater reliability of the subscales (varying from Cronbach's $\alpha 0.49$ for positive self-image to Cronbach's $\alpha 0.79$ for care relation). The QUALIDEM was completed after an observation period of one week. Following Oudman and Zwart ${ }^{12}$ and Oudman and Wijnia, ${ }^{15}$ the score on each subscale was linearly transformed from 0 to 100 , with higher scores reflecting a better quality of life.

The $\mathrm{MoCA}^{17}$ was administered and scored by a psychologist to assess global cognitive functioning. The standard version (7.1) was administered at baseline (T1) and the 7.2 version was administered at follow-up (T2). The MoCA total scores were used in the current study.

Thirty professional carers from the experimental institutions and eleven professional carers from the control institution were asked to complete a self-report questionnaire on their professional experience to identify and rule out important differences between the carers who completed the QUALIDEM. The questionnaire was completed before the start of the experiment, so both groups of carers did not receive any information about EL from the authors. However, the caregivers knew whether they were assigned to the experimental or control institution. This self-report questionnaire contained questions about the number of years of experience in health care, and more specifically, in the care for patients with KS. It also contained questions about their expertise (eg, "how familiar are you with the symptoms of the KS"), openness to trying new methods (eg, "how important is it for you to implement new methods in your work?"), and expectations of the effectiveness of EL (eg, "Do you expect that
EL improves the quality of life of the patients?"). Caregivers rated answers on a 7-point scale.

\section{Analyses}

Nonparametric statistical analyses were performed, as the normality assumption was violated for most subscales. Mann-Whitney- $U$-tests were used to compare the groups baseline performance on the QUALIDEM subscales. Wilcoxon signed-rank tests were performed to examine QUALIDEM subscale scores over time (T1 and T2) in the EL group and the control group.

The QUALIDEM and MoCA were administered at baseline (T1) and at the end (T2) of the study. The difference scores were calculated by subtracting the scores obtained at the start from the scores obtained at the end $(\mathrm{T} 2-\mathrm{T} 1)$. Spearman rank correlation coefficients (two-tailed) were computed between the QUALIDEM difference subscale scores and MoCA difference score in the EL group and the control group, as most difference scores were not normally distributed.

\section{Results \\ Demographics}

One patient in the EL group was excluded because of possible dementia. The EL group consisted of 51 patients (38 men; mean age $=59.9$, range $46-73$ years $)$. The control group consisted of 31 patients ( 22 men; mean age $=62.2$, range 49-74 years), who received care as usual. Table 1 summarizes the group characteristics. The groups did not differ significantly with respect to age, sex distribution, time in nursing home, MoCA total score, or educational level. Educational level was measured in accordance with the Dutch educational system using a 7-point rating scale, ranging from 1 is (less than primary education) to 7 (university degree). Both groups had median scores of 4 (range $=1-6$ ).

Table I Characteristics of the EL group and the control group

\begin{tabular}{llll}
\hline Characteristics & $\begin{array}{l}\text { EL group } \\
(\mathbf{n}=\mathbf{5} \text { I) }\end{array}$ & $\begin{array}{l}\text { Control group } \\
(\mathbf{n}=\mathbf{3} \text { I) }\end{array}$ & p-value \\
\hline Age (years) & $59.9(6.3)$ & $62.2(8 . I)$ & $\mathrm{ns}$ \\
Sex (male/female) & $38 / 13$ & $22 / 9$ & $\mathrm{~ns}$ \\
Education (level) & $4(I-6)$ & $4(I-6)$ & $\mathrm{ns}$ \\
Time in nursing home & $6.8(5.9)$ & $7.9(6.6)$ & $\mathrm{ns}$ \\
(years) & & & $\mathrm{ns}$ \\
MoCA total score & $16.1(4.7)$ & $15.1(3.5)$ & $\mathrm{in}$ \\
\hline
\end{tabular}

Notes: Mean and standard deviations are presented for age, time in nursing home, and MoCA total score, frequency scores are given for the variable 'sex', and median and range are presented for education. Educational code, the level of formal education, was assessed using seven categories based on a Dutch classification system using a 7-point rating scale, ranging from I to (less than primary education) to 7 (university degree). ns results $(p>0.05)$ were obtained.

Abbreviations: EL, errorless learning; MoCA, Montreal Cognitive Assessment, version 7.I; ns, nonsignificant. 
Table 2 Characteristics of the caregivers who rated patients with $\mathrm{KS}$ in the EL group and the control group

\begin{tabular}{|c|c|c|c|}
\hline Group demographics & $\begin{array}{l}\text { EL group } \\
(n=30)\end{array}$ & $\begin{array}{l}\text { Control group } \\
(n=I I)\end{array}$ & $p$-value \\
\hline $\begin{array}{l}\text { Years of experience in } \\
\text { health care }\end{array}$ & $20.5(9.9)$ & $19.8(9.2)$ & ns \\
\hline Years of experience with KS & $12.0(8.2)$ & I I.5 (7.0) & ns \\
\hline Familiar with causes of $\mathrm{KS}^{\mathrm{a}}$ & $6.2(0.7)$ & $6.6(0.5)$ & ns \\
\hline Familiar with symptoms of $\mathrm{KS}^{\mathrm{a}}$ & $6.1(0.6)$ & $6.4(0.5)$ & ns \\
\hline $\begin{array}{l}\text { It is important to implement } \\
\text { new methods }{ }^{\mathrm{a}}\end{array}$ & $6.1(1.0)$ & $6.2(1.0)$ & ns \\
\hline EL improves quality of life ${ }^{a}$ & $6.4(0.7)$ & $5.8(0.9)$ & 0.049 \\
\hline
\end{tabular}

Table 2 summarizes the group characteristics of the professional carers from the experimental and control institution. Significant differences between the groups of caregivers who completed the QUALIDEM for the patients were only found on the question: "Do you expect that errorless learning improves the quality of life of the patients?" $(Z=-2.2$, $p=0.049$ ). The caregivers from the experimental institution had higher expectations of the effects of EL on quality of life than the caregivers from the control institution.

\section{Baseline QUALIDEM scores}

Mean scores and standard deviations on the QUALIDEM subscales for the EL group and the control group at baseline are presented in Table 3. The EL group and the control group only differed significantly at baseline on the subscale "restless behavior" ( $\mathrm{U}=464.0, \mathrm{Z}=-3.1, p=0.002)$, with the EL group showing more restless behavior than the controls. The two groups did not differ significantly on the other subscales.

\section{QUALIDEM scores over time}

Mean scores and standard deviations on the QUALIDEM subscales at T1 and T2 for the EL group and the control group are presented in Table 3. Wilcoxon signed-rank tests showed that scores on the subscales "caregiver relation" $(\mathrm{Z}=-2.78, p=0.005)$, "negative affect" $(\mathrm{Z}=-2.30$, $p=0.022)$, "restless behavior" $(\mathrm{Z}=-2.55, p=0.011)$, "positive self-image" $(\mathrm{Z}=-2.76, p=0.006)$, "social relations" $(\mathrm{Z}=-3.27, p=0.001)$, "social isolation" $(\mathrm{Z}=-3.20$, $p=0.001)$, "feeling at home" $(Z=-2.05, p=0.040)$, and "having something to do" $(\mathrm{Z}=-2.72, p=0.007)$ improved significantly over time in the EL group. A marginally significant increase over time was found for the subscale "positive affect" in this group $(\mathrm{Z}=-1.87, p=0.062)$.

In the control group, a significant difference was only found on the subscale "restless behavior" $(\mathrm{Z}=-2.14$, $p=0.033$ ). Interestingly, restless behavior increased over time in this group. No significant differences between $\mathrm{T} 1$ and T2 were found for the other subscales of the QUALIDEM in the control group.

\section{Quality of life and cognitive functioning}

None of the QUALIDEM difference subscale scores correlated significantly with the MoCA difference score in the EL group or the control group (all $p \geq 0.137$ ).

\section{Discussion}

The aim of this study was to examine the effect of EL on quality of life in patients with KS. Quality of life was significantly increased on eight of the nine subscales on a quality-of-life observation scale in the Korsakoff group patients who participated in EL training. There was a trend toward a significant increase in "positive affect" (ie, the ninth

Table 3 Observed quality of life scores in a group of patients with KS trained with EL (EL group) and a group of patients with KS receiving care as usual (control group)

\begin{tabular}{|c|c|c|c|c|c|c|}
\hline \multirow[t]{2}{*}{ QUALIDEM subscales $^{a}$} & \multicolumn{2}{|c|}{ EL group $(n=5 I)$} & \multirow[t]{2}{*}{$p$-value } & \multicolumn{2}{|c|}{ Control group $(n=3 I)$} & \multirow[t]{2}{*}{$p$-value } \\
\hline & Baseline & After 14 months & & Basline & After I I months & \\
\hline Care relationship & $46.7(16.4)$ & $52.5(16.0)$ & $0.005^{*}$ & $47.7(14.4)$ & $45.2(18.6)$ & 0.359 \\
\hline Positive affect & $58.6(15.4)$ & $62.8(13.8)$ & 0.062 & $56.1(16.9)$ & $57.7(17.8)$ & 0.474 \\
\hline Negative affect & $54.4(18.4)$ & $59.6(15.9)$ & $0.022 *$ & $53.8(21.4)$ & $53.5(17.2)$ & 0.664 \\
\hline Restless, tense behavior & $34.3(21.3)$ & $42.0(21.9)$ & $0.011 *$ & $49.5(18.2)$ & $40.9(21.0)$ & $0.033^{*}$ \\
\hline Positive self-image & $57.7(17.8)$ & $66.3(12.9)$ & $0.006 *$ & $62.9(15.2)$ & $62.4(15.2)$ & 0.842 \\
\hline Social relations & $46.9(14.4)$ & $54.7(13.7)$ & $0.001 *$ & $44.5(16.9)$ & $47.0(17.4)$ & 0.258 \\
\hline Social isolation & $50.0(16.0)$ & $58.8(14.0)$ & $0.001 *$ & $55.9(16.1)$ & $50.8(20.1)$ & 0.106 \\
\hline Feeling at home & $52.1(18.7)$ & $58.2(19.8)$ & $0.040^{*}$ & $57.9(15.5)$ & $61.3(19.5)$ & 0.109 \\
\hline Having something to do & $43.9(23.5)$ & $52.9(24.2)$ & $0.007^{*}$ & $42.7(21.1)$ & $43.5(23.9)$ & 0.792 \\
\hline
\end{tabular}

Notes: Data shown as mean (standard deviation). ${ }^{a} Q U A L I D E M$ means scale scores range: $0-100$, higher scores indicate better quality of life. ${ }^{*} p<0.05$.

Abbreviations: EL, errorless learning; KS, Korsakoff's syndrome. 
subscale). In contrast, no changes over time were found on any of the subscales in the control group that did not participate in EL training. The results in the control group are in line with a previous study examining quality of life in patients with KS, showing that quality of life remains relatively stable in this patient group. ${ }^{15}$ Although the average quality of life is rated higher in patients with $\mathrm{KS}$ than, for example, in patients with other forms of dementia, ${ }^{12}$ their quality of life can be considered "moderate" at best. The subscales "care relationship" and "having something to do" were rated particularly low by professional carers in a previous study. ${ }^{10}$ The results of the current study showed that (re)learning everyday tasks might significantly improve most aspects of quality of life in patients with KS, including "care relationship" and "having something to do."

Patients with KS have impaired explicit memory and relatively spared implicit memory processes. ${ }^{18-20}$ EL training has been suggested to be a particularly useful method for patients with amnesia because it does not require error detection and monitoring, that is, memory functions. ${ }^{1}$ So far, only a few studies have examined and demonstrated the efficacy of EL as a method for (re)learning tasks in patients with KS. ${ }^{3-5}$ Subsequently, it has been suggested that successfully (re)learning tasks might improve a patients' sense of competence and independence, and subsequently improve their quality of life. Our study is the first to provide empirical evidence for this hypothesis in patients with KS. The fact that the follow-up data was gathered 5 months after completion of the training in the EL group offers further support for the impact of the intervention, showing that the improvements in quality of life are maintained up to 5 months after the training has been completed.

We did not observe any significant correlations between cognitive functioning and different aspects of quality of life over time. This is in line with studies in (Alzheimer's) dementia, which consistently found no associations between cognitive function (as measured with the Mini-Mental State Examination $)^{21}$ and quality of life in patients with moderate to severe dementia. ${ }^{23-25}$ Factors that negatively affect quality of life in dementia include awareness of memory impairments, depressed mood, severity of irritability, quality of relationship (rated by the patient with dementia), and male gender. ${ }^{22,24,25}$ Future studies should focus further on detecting predictors of quality of life in patients with KS.

This is the first study to systematically examine the effect of EL on quality of life in a relatively large and homogeneous sample of patients with KS. Nevertheless, some limitations of this study have to be acknowledged.
First, the caregivers who completed the observation scales were not blinded to the conditions. Moreover, almost no differences were found between the groups of caregivers from the experimental and control institution who completed the QUALIDEM, except for their expectations of the effect of EL training on quality of life. Both groups of caregivers expected positive results of EL on quality of life in patients with KS, but the caregivers from the experimental institution even more so than the caregivers from the control institution. Although the self-report questionnaires were completed before any of the caregivers received any information on EL from the experimenters, the caregivers knew whether they were assigned to the experimental or control institution, which might have affected the results. It would be valuable for future studies to include blinded raters and match the groups of raters on outcome expectations. Second, we asked caregivers to rate the quality of life of patients with $\mathrm{KS}$, not the patients themselves. We deliberately did not include self-report questionnaires, as patients with KS lack insight into oneself and one's disease, resulting in invalid responses. ${ }^{26,27}$ From a research perspective, however, to be able to further substantiate the validity of the quality of life reports, it may still be relevant to include self-reported quality of life, next to observed quality of life. Third, the QUALIDEM has been developed for assessing quality of life in patients with dementia. However, quality of life for patients with dementia might differ from that in patients with KS. Recently, an observation scale for assessing quality of life in patients with Korsakoff's has been developed: the QUALIKO. ${ }^{28}$ This includes aspects which are not covered in the QUALIDEM, but are important for the quality of life in patients with Korsakoff's, according to specialized Korsakoff caregivers. Two subscales that have been added to the QUALIKO are "autonomy” and "productivity." The QUALIKO was not used in this study because the restretest reliability of the instrument has not been examined and norms are lacking. Future studies on quality of life in patients with KS should, however, also focus on autonomy and productivity in this patient group. Last, unfortunately, information on the duration of alcohol misuse and time since abstinence was missing. In patients with KS, some recovery of alcohol-related brain damage and cognitive deficits has been observed after weeks, months, or even years of abstinence. ${ }^{29-31}$ Moreover, longer duration and severity of the period of alcohol dependence might result in more severe cognitive deficits. It is unclear what the implications of these factors are for the effects of EL. It has been suggested that more severely impaired patients might benefit more from 
EL principles. ${ }^{32}$ Future studies should include information on the duration and severity of alcohol use and also use an abstinence period of at least 6 weeks before testing. ${ }^{31}$

\section{Conclusion}

Our study is the first to examine the effects of participating in an EL training on quality of life in patients with KS. Despite severe memory impairments, patients with KS still have the potential to (partially) (re)learn tasks using EL. This potential should be exploited, as the successes of (re)learning might improve the quality of life of Korsakoff patients in nursing homes.

\section{Acknowledgments}

We thank the trainers and patients that participated in this study. This research was supported by the Korsakov Kenniscentrum (KKC) [Korsakoff Knowledge Centre]. We thank the participating institutions: Atlant, MeanderGroep, and ZorgAccent. We thank Ans Oosterwechel, Sandy Kramer, Kristel Hakke, Anja Tijmense, and Bettine van der Heide, in particular, for their help with the coordination of the project.

\section{Disclosure}

The authors report no conflicts of interest in this work.

\section{References}

1. Clare L, Jones RS. Errorless learning in the rehabilitation of memory impairment: a critical review. Neuropsychol Rev. 2008;18(1):1-12.

2. de Werd MM, Boelen D, Rikkert MG, Kessels RP. Errorless learning of everyday tasks in people with dementia. Clin Interv Aging. 2013;(8):1177-1190.

3. Komatsu SI, Mimura M, Kato M, Wakamatsu N, Kashima H. Errorless and effortful processes involved in the learning of face-name associations by patients with alcoholic Korsakoff's syndrome. Neuropsychol Rehabil. 2000;10(2):113-132.

4. Kessels RP, van Loon E, Wester AJ. Route learning in amnesia: a comparison of trial-and-error and errorless learning in patients with the Korsakoff syndrome. Clin Rehabil. 2007;21(10):905-911.

5. Oudman E, Nijboer TC, Postma A, et al. Acquisition of an instrumental activity of daily living in patients with Korsakoff's syndrome: a comparison of trial and error and errorless learning. Neuropsychol Rehabil. 2013;23(6):888-913.

6. Cermak LS, Butters N, Goodglass H. The extent of memory loss in Korsakoff patients. Neuropsychologia. 1971;9(3):307-315.

7. Kopelman MD, Thomson AD, Guerrini I, Marshall EJ. The Korsakoff syndrome: clinical aspects, psychology, and treatment. Alcohol Alcoholism. 2009;44(2):148-154.

8. Squire LR. Comparisons between forms of amnesia: some deficits are unique to Korsakoff's syndrome. J Exp Psychol Learn. 1982;8(6): $560-571$.

9. Van Oort R, Kessels RP. Executive dysfunction in Korsakoff's syndrome: time to revise the DSM criteria for alcohol-induced persisting amnestic disorder? Int J Psychiatry Clin Pract. 2009;13(1):78-81.

10. Cohen M, Ylvisaker M, Hamilton J, Kemp L, Claiman B. Errorless learning of functional life skills in an individual with three aetiologies of severe memory and executive function impairment. Neuropsychol Rehabil. 2010;20(3):355-376.
11. Bertens D, Kessels RP, Boelen DH, Fasotti L. Transfer effects of errorless goal management training on cognitive function and quality of life in brain-injured persons. NeuroRehabilitation. 2016;38(1):79-84.

12. Oudman E, Zwart E. Quality of life in patients with Korsakoff's syndrome and patients with dementia: a cross-sectional study. $J$ Am Med Dir Assoc. 2012;13(9):778-781.

13. Ettema TP, Dröes RM, de Lange J, Mellenbergh GJ, Ribbe MW. QUALIDEM: development and evaluation of a dementia specific quality of life instrument. Scalability, reliability, and internal structure. Int $J$ Geriatr Psychiatry. 2007;22(6):549-556.

14. Ettema TP, Dröes RM, de Lange J, Mellenbergh GJ, Ribbe MW. QUALIDEM: development and evaluation of a dementia specific quality of life instrument - validation. Int J Geriatr Psychiatry. 2007;22(5): 424-430.

15. Oudman E, Wijnia JW. Evolution of quality of life in patients with Korsakoff's syndrome in a long-term care facility. Int Psychogeriatr. 2014;26(12):2073-2079.

16. APA. Diagnostic and Statistical Manual of Mental Disorders. DSM-5. Washington, DC: American Psychiatric Association; 2013.

17. Nasreddine ZS, Phillips NA, Be'dirian V, et al. The Montreal Cognitive Assessment, MoCA: a brief screening tool for mild cognitive impairment. J Am Geriatr Soc. 2005;53(4):695-699.

18. Hayes SM, Fortier CB, Levine A, Milberg WP, McGlinchey R. Implicit memory in Korsakoff's syndrome: a review of procedural learning and priming studies. Neuropsychol Rev. 2012;22(2):132-153.

19. Kessels RP, Kopelman MD. Context memory in Korsakoff's syndrome. Neuropsychol Rev. 2012;22(2):117-131.

20. Oudman E, Nijboer TC, Postma A, Wijnia JW, Van der Stigchel S. Procedural learning and memory rehabilitation in Korsakoff's syndromeA review of the literature. Neuropsychol Rev. 2015;25(2):134-148.

21. Folstein MF, Folstein SE, McHugh PR. "Mini-Mental State": a practical method for grading the cognitive state of patients for the clinician. J Psychiatr Res. 1975;12(3):189-198.

22. Hoe J, Hancock G, Livingston G, Orrell M. Quality of life of people with dementia in residential care homes. Br J Psychiatry. 2006;188(5): 460-464.

23. Shin HY. A preliminary study on the Korean version of quality of lifeAlzheimer's disease (QOL-AD) scale in community-dwelling elderly with dementia. J Prev Med Public Health. 2006;39:243-248.

24. Woods RT, Nelis SM, Martyr A, et al. What contributes to a good quality of life in early dementia? Awareness and the QoL-AD: A cross-sectional study. Health Qual Life Outcomes. 2014;12(1):94.

25. Trigg R, Watts S, Jones R, Tod A. Predictors of quality of life ratings from persons with dementia: The role of insight. Int $J$ Geriatr Psychiatry. 2011;26(1):83-91.

26. Egger JI, Wester AJ, De Mey HR, Derksen JJ. Korsakoff's syndrome on the MMPI-2. Acta Neuropsychiatr. 2002;14(5):231-236.

27. Walvoort SJ, van der Heijden PT, Kessels RP, Egger JI. Measuring illness insight in patients with alcohol-related cognitive dysfunction using the Q8 questionnaire: a validation study. Neuropsychiatr Dis Treat. 2016;12:1609-1615.

28. Knirsch P. QUALIKO: Constructie en betrouwbaarheid van een meetinstrument voor kwaliteit van leven bij mensen met het syndroom van Korsakov [QUALIKO: Construction and reliability of a quality of life instrument for people with Korsakoff's syndrome] (bachelor's thesis); 2013. Available from: http://essay.utwente.nl/64146/. Accessed October 28, 2017.

29. Fein G, Torres J, Price L, DiScalfani V. Cognitive performance in long-term abstinent alcoholic individuals. Alcohol Clin Exp Res. 2006; 30:1538-1544.

30. Pitel AL, Rivier J, Beaunieux H, Vabret F, Desgranges B, Eustache F. Changes in the episodic memory and executive functions of abstinent and relapsed alcoholics over a 6-month period. Alcohol Clin Exp Res. 2009;33:490-498

31. Walvoort SJ, Wester AJ, Egger JL. The neuropsychology of neurocognitive functions in alcohol abstinence. Tijdschr Psychiatr. 2013;55:101-111.

32. Evans JJ, Wilson BA, Schuri U, et al. A comparison of "errorless" and "trial-and-error" learning methods for teaching individuals with acquired memory deficits. Neuropsychol Rehabil. 2000;10:67-101. 
Neuropsychiatric Disease and Treatment

Dovepress

\section{Publish your work in this journal}

Neuropsychiatric Disease and Treatment is an international, peerreviewed journal of clinical therapeutics and pharmacology focusing on concise rapid reporting of clinical or pre-clinical studies on a range of neuropsychiatric and neurological disorders. This journa is indexed on PubMed Central, the 'PsycINFO' database and CAS,

and is the official journal of The International Neuropsychiatric Association (INA). The manuscript management system is completely online and includes a very quick and fair peer-review system, which is all easy to use. Visit http://www.dovepress.com/testimonials.php to read real quotes from published authors.

Submit your manuscript here: http://www.dovepress.com/neuropsychiatric-disease-and-treatment-journal 